\title{
(DS)-WEAK COMMUTATIVITY CONDITION AND COMMON FIXED POINT IN INTUITIONISTIC MENGER SPACES
}

\author{
Sushil Sharma $^{\mathrm{a}}$, Bhavana Deshrande $^{\mathrm{b}, *}$ And Suresh Chouhan ${ }^{\mathrm{c}}$
}

\begin{abstract}
The aim of this paper is to define a new commutativity condition for a pair of self mappings i.e., (DS)-weak commutativity condition, which is weaker that compatibility of mappings in the settings of intuitionistic Menger spaces. We show that a common fixed point theorem can be proved for nonlinear contractive condition in intuitionistic Menger spaces without assuming continuity of any mapping. To prove the result we use (DS)-weak commutativity condition for mappings. We also give examples to validate our results.
\end{abstract}

\section{INTRODUCTION}

Probabilistic metric spaces are generalizations of metric spaces which have been introduced by Menger [26]. The space proposed by Menger-Menger space- may have very important applications in quantum particle physics, particularly in connection with both string and E-infinity theories which were given and studied by EI Naschie $[8,9]$. It is believed that E-infinity may be the first general theory which can calculate $\overline{\alpha_{0}}$ (electromegnatic fine structure constant) from first principles rather than just accept it is an experimental quantity determined in the laboratory [10]. Schweizer and Sklar [36] studied the properties of spaces introduced by Menger and gave some basic results on these spaces. They studied topology, convergence of sequence, continuity of mappings, defined the completeness of these spaces, etc. Following Serstnev [38] Sherwood gave a notion of probabilistic metric spaces in [45]. Also, in the same paper Sherwood proved a theorem of a characterization of nested, closed sequence of non-empty sets in complete probabilistic metric space.

Received by the editors July 3, 2010. Revised January 29, 2011. Accepted June 2, 2011.

2000 Mathematics Subject Classification. 54H25, 47H10.

Key words and phrases. common fixed point, intutionistic Menger space, (DS)-weak commutativity, IM-strongly bounded set.

${ }^{*}$ Corresponding author. 
On the other hand, fixed point theory is one of the most famous mathematical theories with application in several branches of science, especially in chaos theory, game theory, theory of differential equations etc.

Kutukcu, Tuna, Yakut [24] introduced notation of intuitionistic Menger spaces with the help of t-norms and t-conorms as a generalization of Menger spaces due to Menger [26]. They defined Housedorff topology on this intuitionistic Menger space and showed that every metric induces an intuitionistic probabilistic metric. They also studied convergence of sequence and completeness of these spaces.

Recently, fixed point theorems in Menger spaces and probabilistic metric spaces have been proved by many authors ([5], [7], [21], [27], [41]- [43], [49]) including Bylka [3], Pathak, Kang and Baek [32], Stojakovic [46]-[48], Hadzic [16]-[19], Dadic and Sarapa [6], Rashwan and Hedar [35], Mishra [27], Radu ([33], [34]), Sehgal and Bharucha-Reid [37], Cho, Murthy and Stojakovic [4], Sharma and Bagvan [39], Sharma and Deshpande [40], Sharma, Deshpande and Tiwari [44], Kubiaczyv and Deshpande [23].

There are many generalizations of commutativity for function defined on spaces with non-deterministic distance (probabilistic metric spaces, fuzzy metric spaces etc.) which have an important role in the statements guaranteeing the existence of common fixed points.

Pant [29] initiated the study of noncompatible mappings and introduced R-weak commutativity for a pair of mappings in metric spaces. Jungck and Rhoades [22] defined weak commutativity for a pair of mappings and showed that weak commutativity of a pair of mappings is weaker then compatibility for a pair of mappings. Pathak, Cho and Kang [31] introduced the concept of R-weakly commuting mapping of type (A) in metric spaces and showed that this type of mapping is non compatible. They also showed that R-weakly commuting mapping is not necessarily R-weakly commuting mapping of type (A). Sharma and Deshpande [41] introduced the concept of R-weak commuting mappings of type (A) in the settings of fuzzy metric spaces and defined (DS)-weak commutativity in fuzzy metric spaces.

Recently Deshpande [7] introduced the notion of (DS)-weak commutativity in intuitionistic fuzzy metric spaces.

Most of the properties which provide the existence of fixed points and common fixed points are of linear contractive type condition 
The result in fixed point theory with non-linear type contractive condition were given by Boyd and Wong [2], Jesic and Babacev [21], O'regan and Sadaati [28] and recently by Deshpande [7]

The purpose of this paper is to define (DS)-weak commutativity in the settings of intuitionistic Menger spaces and prove a common fixed point theorem with non linear contractive condition for a pair of mappings under the assumption of (DS)weak commuting mappings without assuming continuity of any mapping. Our result improves the previous results. We also give examples to validate our results.

\section{Preliminaries}

Definition 2.1. A binary operation $\mathrm{T}:[0,1] \mathrm{x}[0,1] \longrightarrow[0,1]$ is a t-norm if $\mathrm{T}$ satisfies the following conditions : (a) $\mathrm{T}$ is commutative and associative (b) $\mathrm{T}(\mathrm{a}, 1)=\mathrm{a}$ for all $\mathrm{a} \in[0,1](\mathrm{c}) \mathrm{T}(\mathrm{a}, \mathrm{b}) \leq \mathrm{T}(\mathrm{c}, \mathrm{d})$ whenever $\mathrm{a} \leq \mathrm{c}$ and $\mathrm{b} \leq \mathrm{d}$ and $\mathrm{a}, \mathrm{b}, \mathrm{c}, \mathrm{d} \in[0,1]$.

Definition 2.2. A binary operation $\mathrm{S}:[0,1] \times[0,1] \rightarrow[0,1]$ is a t-conorm if $\mathrm{S}$ satisfies the following conditions : (a) $\mathrm{S}$ is commutative and associative (b) $\mathrm{S}(\mathrm{a}, 0)=\mathrm{a}$ for all $\mathrm{a} \in[0,1]:(\mathrm{c}) \mathrm{S}(\mathrm{a}, \mathrm{b}) \leq \mathrm{S}(\mathrm{c}, \mathrm{d})$ whenever $\mathrm{a} \leq \mathrm{c}$ and $\mathrm{b} \leq \mathrm{d}$ and $\mathrm{a}, \mathrm{b}, \mathrm{c}, \mathrm{d} \in[0,1]$.

Remark 2.1. The concepts of t-norms $\mathrm{T}$ and t-conorms $\mathrm{S}$ are known as the axiomatic skeletons that we use for characterizing fuzzy intersections and union, respectively. These concepts were originally introduced by Menger [26] in his study of statistical metric spaces. Several examples for these concepts were proposed by many authors $[1,11,12,13,14,15,25]$. In [30] we also have (a) for any a,b $\in(0,1)$ with $a>b$, there exists $\mathrm{c}, \mathrm{d} \in(0,1)$ such that $\mathrm{T}(\mathrm{a}, \mathrm{c}) \geq \mathrm{b}, \mathrm{S}(\mathrm{b}, \mathrm{d}) \leq \mathrm{a}$; (b) for any a $\in(0,1)$, these exists $\mathrm{b}, \mathrm{c} \in(0,1)$ such that $\mathrm{T}(\mathrm{b}, \mathrm{b}) \geq \mathrm{a}, \mathrm{S}(\mathrm{c}, \mathrm{c}) \leq \mathrm{a}$ through out this paper, we will denote $\mathrm{R}=(-\infty, \infty)$ and $\mathrm{R}^{+}=[0, \infty)$.

Definition $2.3([20])$. A distance distribution function is a function $\mathrm{F}: \mathrm{R} \rightarrow \mathrm{R}^{+}$ which is left continuous on $R$, non decreasing and $\inf _{t \in R} F(t)=0, \sup _{t \in R} F(t)=1$. We will denote by $\mathrm{D}$ the family of all distance distribution functions and by $\mathrm{H}$ a special element of D defined by

$$
H(t)=\left\{\begin{array}{ll}
0 & \text { if } t \leq 0 \\
1 & \text { if } t>0
\end{array} .\right.
$$

If $\mathrm{X}$ is a non empty set, $\mathrm{F}: \mathrm{X} \times \mathrm{X} \rightarrow \mathrm{D}$ is called a probabilistic distance on $\mathrm{X}$ and $\mathrm{F}(\mathrm{x}, \mathrm{y})$ is usually denoted by $\mathrm{F}_{\mathrm{x}, \mathrm{y}}$. 
Definition 2.4. A non distance distribution function is a function $L: R \rightarrow R^{+}$which is right continuous on $\mathrm{R}$, non increasing and $\inf _{\mathrm{t}} \in \mathrm{R} \mathrm{L}(\mathrm{t})=1$, $\sup _{\mathrm{t}} \in \mathrm{R} \mathrm{L}(\mathrm{t})=0$. We will denote by $\mathrm{E}$ the family of all non-distance distribution functions and by $\mathrm{G}$ a special element of $\mathrm{E}$ defined by

$$
G(t)=\left\{\begin{array}{ll}
1 & \text { if } t \leq 0 \\
0 & \text { if } t>0
\end{array} .\right.
$$

If $\mathrm{X}$ is a non empty set, $\mathrm{L}: \mathrm{X} \mathrm{x} \mathrm{X} \rightarrow \mathrm{E}$ is called a probabilistic non-distance on $\mathrm{X}$ and $\mathrm{L}(\mathrm{x}, \mathrm{y})$ is usually denoted by $\mathrm{L}_{\mathrm{x}, \mathrm{y}}$.

Definition 2.5 ([24]). A triple (X, F, L) is said to be an intuitionistic probabilistic metric space if $\mathrm{X}$ is a non empty set, $\mathrm{F}$ is a probabilistic distance and $\mathrm{L}$ is a probabilistic non-distance on $\mathrm{X}$ satisfying the following conditions for all $\mathrm{x}, \mathrm{y}, \mathrm{z} \in \mathrm{X}, \mathrm{t}, \mathrm{s} \geq$ 0
(a) $\mathrm{L}_{\mathrm{x}, \mathrm{y}}(\mathrm{t})+\mathrm{F}_{\mathrm{x}, \mathrm{y}}(\mathrm{t}) \leq 1$
(b) $\mathrm{F}_{\mathrm{x}, \mathrm{y}}(0)=0$
(c) $\mathrm{F}_{\mathrm{x}, \mathrm{y}}(\mathrm{t})=\mathrm{H}(\mathrm{t})$ if and only if $\mathrm{x}=\mathrm{y}$
(d) $\mathrm{F}_{\mathrm{x}, \mathrm{y}}(\mathrm{t})=\mathrm{F}_{\mathrm{y}, \mathrm{x}}(\mathrm{t})$
(e) If $\mathrm{F}_{\mathrm{x}, \mathrm{z}}(\mathrm{t})=1$ and $\mathrm{F}_{\mathrm{z}, \mathrm{y}}(\mathrm{s})=1$, then $\mathrm{F}_{\mathrm{x}, \mathrm{y}}(\mathrm{t}+\mathrm{s})=1$
(f) $\mathrm{L}_{\mathrm{x}, \mathrm{y}}(0)=1$
(g) $\mathrm{L}_{\mathrm{x}, \mathrm{y}}(\mathrm{t})=\mathrm{G}(\mathrm{t})$, if and only if $\mathrm{x}=\mathrm{y}$
(h) $\mathrm{L}_{\mathrm{x}, \mathrm{y}}(\mathrm{t})=\mathrm{L}_{\mathrm{y}, \mathrm{x}}(\mathrm{t})$
(i) If $\mathrm{L}_{\mathrm{x}, \mathrm{z}}(\mathrm{t})=0$ and $\mathrm{L}_{\mathrm{z}, \mathrm{y}}(\mathrm{s})=0$, then $\mathrm{L}_{\mathrm{x}, \mathrm{y}}(\mathrm{t}+\mathrm{s})=0$

If, in addition the triangle inequalities
(j) $\mathrm{F}_{\mathrm{x}, \mathrm{y}}(\mathrm{t}+\mathrm{s}) \geq \mathrm{T}\left(\mathrm{F}_{\mathrm{x}, \mathrm{z}}(\mathrm{t}), \mathrm{F}_{\mathrm{z}, \mathrm{y}}(\mathrm{s})\right)$
(k) $\mathrm{L}_{\mathrm{x}, \mathrm{y}}(\mathrm{t}+\mathrm{s}) \leq \mathrm{S}\left(\mathrm{L}_{\mathrm{x}, \mathrm{z}}(\mathrm{t}), \mathrm{L}_{\mathrm{z}, \mathrm{y}}(\mathrm{s})\right)$,

where $\mathrm{T}$ is a t-norm and $\mathrm{S}$ is a t-conorm are satisfied, then $(\mathrm{X}, \mathrm{F}, \mathrm{L}, \mathrm{T}, \mathrm{S})$ is said to be an intuitionistic Menger space. The functions $\mathrm{F}_{\mathrm{x}, \mathrm{y}}(\mathrm{t})$ and $\mathrm{L}_{\mathrm{x}, \mathrm{y}}(\mathrm{t})$ denote the degree of nearness and the degree of non-nearness between $\mathrm{x}$ and $\mathrm{y}$ with respect to $\mathrm{t}$, respectively.

Remark 2.2 ([24]). Every Menger space (X, F, T) is an intuitionistic Menger space of the form (X, F, 1-F, T, S) such that t-norm T and t-conorm S are associated [24], i.e., $\mathrm{S}(\mathrm{x}, \mathrm{y})=1-\mathrm{T}(1-\mathrm{x}, 1-\mathrm{y})$ for any $\mathrm{x}, \mathrm{y} \in \mathrm{X}$.

Example 2.1 ([24]). (Induced intuitionistic probabilistic metric) Let (X,d) be a metric space. Then the metric $\mathrm{d}$ induces a distance distribution function $\mathrm{F}$ defined by 
$\mathrm{F}_{\mathrm{x}, \mathrm{y}}(\mathrm{t})=\mathrm{H}(\mathrm{t}-\mathrm{d}(\mathrm{x}, \mathrm{y}))$ and a non-distance distribution function $\mathrm{L}$ defined by $\mathrm{L}_{\mathrm{x}, \mathrm{y}}(\mathrm{t})=$ $\mathrm{G}(\mathrm{t}-\mathrm{d}(\mathrm{x}, \mathrm{y}))$ for all $\mathrm{x}, \mathrm{y} \in \mathrm{X}$ and $\mathrm{t} \geq 0$ then $(\mathrm{X}, \mathrm{F}, \mathrm{L})$ is an intuitionistic probabilistic metric space. We call this intuitionistic probabilistic metric space induced by a metric $\mathrm{d}$ the induced intuitionistic probabilistic metric space. It t-norm $\mathrm{T}$ is $\mathrm{T}(\mathrm{a}$, $\mathrm{b})=\min \{\mathrm{a}, \mathrm{b}\}$ and $\mathrm{t}$-conorm $\mathrm{S}$ is $\mathrm{S}(\mathrm{a}, \mathrm{b})=\min \{1, \mathrm{a}+\mathrm{b}\}$ for all $\mathrm{a}, \mathrm{b} \in[0,1]$ then $\left(\mathrm{X}, \mathrm{F}, \mathrm{L}, \mathrm{T}_{\mathrm{M}}, \mathrm{S}_{\mathrm{M}}\right)$ is an intuitionistic Menger space.

Remark 2.3 ([24]). Note that the above example holds even with the t-norm T(a, $\mathrm{b})=\min \{\mathrm{a}, \mathrm{b}\}$ and $\mathrm{t}$-conorm $\mathrm{S}$ is $\mathrm{S}(\mathrm{a}, \mathrm{b})=\max \{\mathrm{a}, \mathrm{b}\}$ and hence $(\mathrm{X}, \mathrm{F}, \mathrm{L}, \mathrm{T}, \mathrm{S})$ is an intuitionistic Menger space with respect to any t-norm and t-conorm. Also note that, in the above example t-norm $\mathrm{T}$ and t-conorm $\mathrm{S}$ are not associated.

Theorem 2.1 ([24]). Let (X, F, L) be an intuitionistic probabilistic space, T,S be binary operations on $[0,1] \times[0,1]$ into $[0,1]$ satisfying $\mathrm{T}(\mathrm{a}, \mathrm{b}) \leq \mathrm{T}(\mathrm{c}, \mathrm{d}), \mathrm{S}(\mathrm{a}, \mathrm{b}) \leq$ $\mathrm{S}(\mathrm{c}, \mathrm{d})$ for a,b,c,d $\in[0,1]$ such that $\mathrm{a} \leq \mathrm{c}, \mathrm{b} \leq \mathrm{d}$ and $\sup _{t<1} T(t, t)=1, \inf _{t<1} S(1-$ $t, 1-t)=0$, respectively. Then the family $u=\left\{U_{\epsilon, \lambda}\right\}_{\epsilon>0, \lambda \in(0,1)}$ where $U_{\epsilon, \lambda}=\{(x, y) \in$ $\left.X \times X: F_{x, y}(\epsilon)>1-\lambda, L_{x, y}(\epsilon)>\lambda\right\}$ is a base for a Hausdorff uniformity on $\mathrm{X} \times \mathrm{X}$.

Theorem 2.2 ([24]). Let (X, F, L) be an intuitionistic probabilistic metric space satisfies the hypotheses of Theorem 2.1 Then for a sequence $\left\{\mathrm{x}_{n}\right\}$ in $\mathrm{X}, \mathrm{x}_{n} \rightarrow \mathrm{x}$ if and only if $\mathrm{F}_{\mathrm{x}, \mathrm{x}_{\mathrm{n}}}(\mathrm{t}) \rightarrow 1$ and $\mathrm{L}_{\mathrm{x}, \mathrm{x}_{\mathrm{n}}}(\mathrm{t}) \rightarrow 0$ as $\mathrm{n} \rightarrow \infty$.

Definition 2.6 ([24]). Let (X, F, L, T, S) be an intuitionistic Menger space with $\sup _{\mathrm{t}<1} \mathrm{~T}(\mathrm{t}, \mathrm{t})=1, \inf _{\mathrm{t}<1} \mathrm{~S}(1-\mathrm{t}, 1-\mathrm{t})=0$.

(a) A sequence $\left\{\mathrm{x}_{n}\right\}$ in $\mathrm{X}$ is said to be a Cauchy sequence if for each $\epsilon>0$ and $\lambda$ $\in(0,1)$ there exists a positive integer $\mathrm{n}_{0}=\mathrm{n}_{0}(\epsilon, \lambda)$ such that $\mathrm{F}_{\mathrm{x}_{\mathrm{n}}, \mathrm{x}_{\mathrm{m}}}(\epsilon)>1-\lambda$ and $\mathrm{L}_{\mathrm{x}_{\mathrm{n}, \mathrm{x}_{\mathrm{m}}}}(\epsilon)<\lambda$ for all $\mathrm{n}, \mathrm{m} \geq \mathrm{n}_{0}$.

(b) An intuitionistic Menger space in which every Cauchy sequence is convergent is said to be complete.

Lemma 2.1 ([24]). Let (X, F, L, T, S) be an intuitionistic Menger space with

$$
\sup _{\mathrm{t}<1} \mathrm{~T}(\mathrm{t}, \mathrm{t})=1, \inf _{\mathrm{t}<1} \mathrm{~S}(1-\mathrm{t}, 1-\mathrm{t})=0 .
$$

Let $\left\{x_{n}\right\},\left\{y_{n}\right\}$ be two sequences in $X$ with $\mathrm{x}_{n} \rightarrow \mathrm{x}, \mathrm{y}_{n} \rightarrow \mathrm{y}$ respectively

(a) $\lim _{\mathrm{n} \rightarrow \infty} \inf \mathrm{F}_{\mathrm{x}_{\mathrm{n}, \mathrm{y}_{\mathrm{n}}}}(\mathrm{t}) \geq \mathrm{F}_{\mathrm{x}, \mathrm{y}}(\mathrm{t})$ and $\lim _{\mathrm{n} \rightarrow \infty} \sup \mathrm{L}_{\mathrm{x}_{\mathrm{n}, \mathrm{y}_{\mathrm{n}}}}(\mathrm{t}) \leq \mathrm{L}_{\mathrm{x}, \mathrm{y}}(\mathrm{t})$ for $\mathrm{t} \geq 0$

(b) if $\mathrm{t} \geq 0$ is a continuous point of $\mathrm{F}_{\mathrm{x}, \mathrm{y}}$ and $\mathrm{L}_{\mathrm{x}, \mathrm{y}}$, then $\lim _{\mathrm{n} \rightarrow \infty} \mathrm{F}_{\mathrm{x}_{\mathrm{n}}, \mathrm{y}_{\mathrm{n}}}(\mathrm{t})=\mathrm{F}_{\mathrm{x}, \mathrm{y}}(\mathrm{t})$ and $\lim _{\mathrm{n} \rightarrow \infty} \mathrm{L}_{\mathrm{x}_{\mathrm{n}, \mathrm{y}_{\mathrm{n}}}}(\mathrm{t})=\mathrm{L}_{\mathrm{x}, \mathrm{y}}(\mathrm{t})$. 
Definition 2.7. Let $(\mathrm{X}, \mathrm{F}, \mathrm{L}, \mathrm{T}, \mathrm{S})$ be an intuitionistic Menger space $\mathrm{A} \subseteq \mathrm{X}$. Closure of the set $\mathrm{A}$ is the smallest closed set containing $\mathrm{A}$, denoted by $\vec{A}$.

Obviously, having in mind the Hausdorff topology and the definiton of converging sequence we have the next remark holds.

Remark 2.4. $\mathrm{x} \in \bar{A}$ if and only if there exists a sequence $\left\{\mathrm{x}_{n}\right\}$ in $\mathrm{A}$ such that $\mathrm{x}_{n}$ $\rightarrow \mathrm{x}$.

The concept of probabilistic boundedness was introduced by Sherwood [45]. Park [30] defined intuitionistic fuzzy diameter zero and IM bounded set in intuitionistic fuzzy metric spaces.

Definition 2.8. Let (X, F, L, T, S) be an intuitionistic Menger space A collection $\left\{\mathrm{F}_{n}\right\}_{n \in \mathrm{N}}$ is said to have intutionistic Menger diameter zero if for each $\mathrm{r} \in(0,1)$ any each $\mathrm{t}>0$ there exists $\mathrm{n}_{0} \in \mathrm{N}$ such that $\mathrm{F}_{\mathrm{x}, \mathrm{y}}(\mathrm{t})>1-\mathrm{r}$ and $\mathrm{L}_{\mathrm{x}, \mathrm{y}}(\mathrm{t})<\mathrm{r}$ for all $\mathrm{x}, \mathrm{y} \in$ $\mathrm{F}_{\mathrm{n}_{0}}$.

Theorem 2.3. An intuitionistic Menger space $(\mathrm{X}, \mathrm{F}, \mathrm{L}, \mathrm{T}, \mathrm{S})$ is complete if and only if every nested sequence $\left\{\mathrm{F}_{\mathrm{n}}\right\}_{\mathrm{n} \in \mathrm{N}}$ of non-empty closed sets with intutionistic Menger diameter zero have non-empty intersection.

Proof. First suppose that the given condition is satisfied. We claim that (X, F, L, T, S) is complete. Let $\left\{\mathrm{x}_{n}\right\}$ be a Cauchy sequence in $\mathrm{X}$. Set $\mathrm{B}_{\mathrm{n}}=\left\{\mathrm{x}_{\mathrm{k}}: \mathrm{k} \geq \mathrm{n}\right\}$ and $\mathrm{F}_{\mathrm{n}}=$ $\bar{B}_{\mathrm{n}}$, then we claim that $\left\{\mathrm{F}_{\mathrm{n}}\right\}$ has intuitionistic Menger diameter zero. For given $\mathrm{S}$ $\in(0,1)$ and $\mathrm{t}>0$, we choose $\mathrm{r} \in(0,1)$ such that $\mathrm{T}((1-\mathrm{r}) \mathrm{T}((1-\mathrm{r}),(1-\mathrm{r}))>(1-\mathrm{s})$ and $\mathrm{S}(\mathrm{r}, \mathrm{r}, \mathrm{r})<\mathrm{s}$. Since $\left\{\mathrm{x}_{n}\right\}$ is Cauchy sequence, there exists $\mathrm{n}_{0} \in \mathrm{N}$ such that $\mathrm{F}_{\mathrm{x}_{\mathrm{n}}, \mathrm{x}_{\mathrm{m}}}\left(\frac{\mathrm{t}}{3}\right)$ $>1$-r and $\mathrm{L}_{\mathrm{x}_{\mathrm{n}}, \mathrm{x}_{\mathrm{m}}}\left(\frac{\mathrm{t}}{3}\right)<\mathrm{r}$ for all $\mathrm{n}, \mathrm{m} \geq \mathrm{n}_{0}$. Therefore $\mathrm{F}_{\mathrm{x}, \mathrm{y}}\left(\frac{\mathrm{t}}{3}\right)>1-\mathrm{r}$ and $\mathrm{L}_{\mathrm{x}, \mathrm{y}}\left(\frac{\mathrm{t}}{3}\right)<\mathrm{r}$ for all $\mathrm{x}, \mathrm{y} \in \mathrm{B}_{\mathrm{n}_{0}}$.

Let $\mathrm{x}, \mathrm{y} \in \mathrm{F}_{\mathrm{n}_{0}}$, then there exist sequence $\left\{\mathrm{x}_{n}\right\}$ and $\left\{\mathrm{y}_{n}\right\}$ in $\mathrm{B}_{\mathrm{n}_{0}}$ such that $\mathrm{x}_{n}{ }_{n} \rightarrow$ $\mathrm{x}$ and $\mathrm{y}_{n} \rightarrow \mathrm{y}$. Hence $\mathrm{x}_{n} \in \mathrm{B}\left(\mathrm{x}, \mathrm{r}, \frac{\mathrm{t}}{3}\right)$ and $\mathrm{y}_{n}{ }_{n} \rightarrow \mathrm{B}\left(\mathrm{y}, \mathrm{r}, \frac{\mathrm{t}}{3}\right)$ for sufficiently large $\mathrm{n}$. Now we have

$$
\begin{aligned}
\mathrm{F}_{\mathrm{x}, \mathrm{y}}(\mathrm{t}) & \geq \mathrm{T}\left(\mathrm{F}_{\mathrm{x}, \mathrm{x}_{\mathrm{n}}^{\prime}}\left(\frac{\mathrm{t}}{3}\right), \mathrm{F}_{\mathrm{x}_{\mathrm{n}, \mathrm{y}_{\mathrm{n}}^{\prime}}}\left(\frac{\mathrm{t}}{3}\right), \mathrm{F}_{\mathrm{y}_{\mathrm{n}, \mathrm{y}}}\left(\frac{\mathrm{t}}{3}\right)\right) \\
& >\mathrm{T}((1-\mathrm{r}),(1-\mathrm{r}),(1-\mathrm{r})) \\
& >1-\mathrm{s} \text { and } \\
\mathrm{L}_{\mathrm{x}, \mathrm{y}}(\mathrm{t}) & \geq \mathrm{S}\left(\mathrm{L}_{\mathrm{x}, \mathrm{x}_{\mathrm{n}}^{\prime}}\left(\frac{\mathrm{t}}{3}\right), \mathrm{L}_{\mathrm{x}_{\mathrm{n}}, \mathrm{y}_{\mathrm{n}}^{\prime}}\left(\frac{\mathrm{t}}{3}\right), \mathrm{L}_{\mathrm{y}_{\mathrm{n}, \mathrm{y}}^{\prime}}\left(\frac{\mathrm{t}}{3}\right)\right) \\
& <\mathrm{S}(\mathrm{r}, \mathrm{r}, \mathrm{r})<\mathrm{s} .
\end{aligned}
$$


Therefore $\mathrm{F}_{\mathrm{x}, \mathrm{y}}(\mathrm{t})>1-\mathrm{s}$ and $\mathrm{L}_{\mathrm{x}, \mathrm{y}}(\mathrm{t})<\mathrm{s}$ for all $\mathrm{x}, \mathrm{y} \in \mathrm{F}_{\mathrm{n}_{0}}$. Thus $\left\{\mathrm{F}_{n}\right\}$ has intuitionistic Menger diameter zero and hence by hypothesis $\underset{n \in N}{\cap} F_{n}$ is non empty.

Take $\mathrm{x} \in \underset{\mathrm{n} \in \mathrm{N}}{\bigcap} \mathrm{F}_{\mathrm{n}}$ is we show that $\mathrm{x}_{\mathrm{n}} \rightarrow \mathrm{x}$. Then, for $\mathrm{r} \in(0,1)$ and $\mathrm{t}>0$, there exists $n \in N$ such that $F_{x_{n}, x}(t)>1-r$ and $L_{x_{n}, x}(t)<r$ for all $n \geq N$. Therefore, for each $\mathrm{t}>0, \mathrm{~F}_{\mathrm{x}_{\mathrm{n}}, \mathrm{x}}(\mathrm{t}) \rightarrow 1$ and $\mathrm{L}_{\mathrm{x}_{\mathrm{n}}, \mathrm{x}}(\mathrm{t}) \rightarrow 0$ as $\mathrm{n} \rightarrow \infty$ and hence $\mathrm{x}_{\mathrm{n}} \rightarrow \mathrm{x}$. Therefore $(\mathrm{X}, \mathrm{F}, \mathrm{L}, \mathrm{T}, \mathrm{S})$ is complete.

Conversely, suppose that $(\mathrm{X}, \mathrm{F}, \mathrm{L}, \mathrm{T}, \mathrm{S})$ is complete and $\left\{\mathrm{F}_{\mathrm{n}}\right\}_{\mathrm{n} \in \mathrm{N}}$ is nested sequence of nonempty closed sets with intuitionistic Menger diameter zero. For each $\mathrm{n} \in \mathrm{N}$, choose a point $\mathrm{x}_{\mathrm{n}} \in \mathrm{F}_{\mathrm{n}}$. We claim that $\left\{\mathrm{x}_{\mathrm{n}}\right\}$ is a Cauchy sequence. Since $\left\{\mathrm{F}_{\mathrm{n}}\right\}$ has intuitionistic Menger diameter zero, for $\mathrm{t}>0$ and $\mathrm{r} \in(0,1)$, there exists $\mathrm{n}_{0}$ $\in \mathrm{N}$ such that $\mathrm{F}_{\mathrm{x}, \mathrm{y}}(\mathrm{t})>1-\mathrm{r}$ and $\mathrm{L}_{\mathrm{x}, \mathrm{y}}(\mathrm{t})<\mathrm{r}$ for all $\mathrm{x}, \mathrm{y} \in \mathrm{F}_{\mathrm{n}_{0}}$. Since $\left\{\mathrm{F}_{\mathrm{n}}\right\}$ is nested sequence $\mathrm{F}_{\mathrm{x}_{\mathrm{n}}, \mathrm{x}_{\mathrm{m}}}(\mathrm{t})>1-\mathrm{r}$ and $\mathrm{L}_{\mathrm{x}_{\mathrm{n}}, \mathrm{x}_{\mathrm{m}}}(\mathrm{t})<\mathrm{r}$ for all $\mathrm{n}, \mathrm{m} \geq \mathrm{n}_{0}$. Hence $\left\{\mathrm{x}_{\mathrm{n}}\right\}$ is a Cauchy sequence. Since $(\mathrm{X}, \mathrm{F}, \mathrm{L}, \mathrm{T}, \mathrm{S})$ is complete, $\mathrm{x}_{\mathrm{n}} \rightarrow \mathrm{x}$ for some $\mathrm{x} \in \mathrm{X}$. Therefore $\mathrm{x} \in$ $\overline{F_{n}}=F_{n}$ for every $n$, and hence $x \in \bigcap_{n \in N} F_{n}$. This completes our proof.

Remark 2.5. The element $x \in \underset{n \in N}{\cap} F_{n}$ is unique.

For if there are two elements $x, y \in \underset{n \in N}{\cap} F_{n}$, Since $\left\{F_{n}\right\}$ has intuitionistic Menger diameter zero, for each fixed $t>0, F_{x, y}(t)>1-\frac{1}{n}$ and $L_{x, y}(t)<\frac{1}{n}$ for each $n \in N$. This implies that $\mathrm{F}_{\mathrm{x}, \mathrm{y}}(\mathrm{t})=1$ and $\mathrm{L}_{\mathrm{x}, \mathrm{y}}(\mathrm{t})=0$ and hence $\mathrm{x}=\mathrm{y}$.

Definition 2.9. Let $(X, F, L, T, S)$ be an intuitionistic Menger space. A subset A of $\mathrm{X}$ is said to be IM-bounded if there exists $\mathrm{t}>0$ and $\mathrm{r} \in(0,1)$ such that $\mathrm{F}_{\mathrm{X}, \mathrm{y}}(\mathrm{t})>$ 1-r and $\mathrm{L}_{\mathrm{x}, \mathrm{y}}(\mathrm{t})>\mathrm{r}$ for all $\mathrm{x}, \mathrm{y} \in \mathrm{A}$.

Definition 2.10. Let $(X, F, L, T, S)$ be an intuitionistic Menger space. Let the mappings $\delta_{A}(\mathrm{t}):(0, \infty) \rightarrow[0,1]$ and $\rho_{A}(\mathrm{t}):(0, \infty) \rightarrow[0,1]$ be defined as

$$
\begin{aligned}
& \delta_{A}(\mathrm{t})=\inf _{\mathrm{x}, \mathrm{y} \in \mathrm{A}} \sup _{\epsilon<\mathrm{t}} \mathrm{F}_{\mathrm{x}, \mathrm{y}}(\epsilon) \text { and } \\
& \rho_{A}(\mathrm{t})=\sup _{\mathrm{inf}} \inf _{\epsilon<\mathrm{t}} \mathrm{L}_{\mathrm{x}, \mathrm{y}}(\epsilon) .
\end{aligned}
$$

The constants $\delta_{A}=\sup _{\mathrm{t}>0} \delta_{A}^{\mathrm{x}, \mathrm{y}}(\mathrm{t}) \underset{\mathrm{A}}{\in}$ and $\rho_{A}=\inf _{\mathrm{t}>0} \rho_{A}(\mathrm{t})$ are known as intuitionistic Menger diameter of nearness and intuitionistic Menger diameter of non-nearness of set A.

Remark 2.6. If $\mathrm{A}$ is an IM-bounded set then the next inequalities $\delta_{A} \geq 1$-r and $\rho_{A} \leq \mathrm{r}$ hold.

Definition 2.11. if $\delta_{A}=1$ and $\rho_{A}=0$ the set A will call IM-strongly bounded set. 
Lemma 2.2. Let $\phi:(0, \infty) \rightarrow(0, \infty)$ be a continuous, nondecreasing function which satisfies $\phi(\mathrm{t})<\mathrm{t}$ for all $\mathrm{t}>0$. Then for all $\mathrm{t}>0$ it holds that $\lim _{\mathrm{n} \rightarrow \infty} \phi^{n}(\mathrm{t})$ $=0$, where $\phi^{n}(\mathrm{t})$ denotes the $\mathrm{n}^{\text {th }}$ iteration of $\phi$.

Proof. For arbitrary $\mathrm{t}>0$, because $\phi(\mathrm{t})<\mathrm{t}$ and $\phi$ is a non decreasing function. by induction it follows that $\phi^{n}(\mathrm{t})>\phi^{n-1}(\mathrm{t})$ and $\phi^{n}(\mathrm{t})<\mathrm{t}$ for all $\mathrm{n} \in \mathrm{N}$. This means that the sequence $\left\{\phi^{n}(\mathrm{t})\right\}_{\mathrm{n}} \in \mathrm{N}$ is monotonically non-increasing. Since it is bounded, it follows that there exists $\mathrm{c} \geq 0$ such that $\lim _{\mathrm{n} \rightarrow \infty} \phi^{n}(\mathrm{t})=\mathrm{c}$.

We claim that $\mathrm{c}=0$. Let us suppose that $\mathrm{c}>0$ from continuity of $\phi$ we get $\mathrm{c}=$ $\lim _{\mathrm{n} \rightarrow \infty} \phi^{n+1}(\mathrm{t})=\lim _{\mathrm{n} \rightarrow \infty} \phi\left(\phi^{n}(\mathrm{t})\right)=\phi(\mathrm{c})<\mathrm{c}$, which is a contradiction.

Lemma 2.3. Let (X, F, L, T, S) be an intuitionistic Menger space. Let $\phi:(0, \infty)$ $\rightarrow(0, \infty)$ be a continuous, nondecreasing function which satisfies $\phi(\mathrm{t})<\mathrm{t}$ for all $\mathrm{t}$ $>0$. Then the following statement hold:

(a) If for all $\mathrm{x}, \mathrm{y} \in \mathrm{X}$ it holds that $\mathrm{F}_{\mathrm{x}, \mathrm{y}} \phi(\mathrm{t}) \geq \mathrm{F}_{\mathrm{x}, \mathrm{y}}(\mathrm{t})$ for all $\mathrm{t}>0$ then $\mathrm{x}=\mathrm{y}$ and

(b) If for all $\mathrm{x}, \mathrm{y} \in \mathrm{X}$ it holds that $\mathrm{L}_{\mathrm{x}, \mathrm{y}} \phi(\mathrm{t}) \leq \mathrm{L}_{\mathrm{x}, \mathrm{y}}(\mathrm{t})$ for all $\mathrm{t}>0$ then $\mathrm{x}=\mathrm{y}$.

Proof. (a) Let us suppose that $\mathrm{F}_{\mathrm{x}, \mathrm{y}} \phi(\mathrm{t}) \geq \mathrm{F}_{\mathrm{x}, \mathrm{y}}(\mathrm{t})$ and $\mathrm{x} \neq \mathrm{y}$. From this condition by induction we have that $\mathrm{F}_{\mathrm{x}, \mathrm{y}} \phi^{n}(\mathrm{t}) \geq \mathrm{F}_{\mathrm{x}, \mathrm{y}}(\mathrm{t})$ Taking limit as $\mathrm{n} \rightarrow \infty$, we get that $\mathrm{F}_{\mathrm{x}, \mathrm{y}}(\mathrm{t})=0$ for all $\mathrm{t}>0$, which is a contradiction so $\mathrm{x}=\mathrm{y}$.

(b) Similarly as the proof of (a).

Definition 2.12. Let $\mathrm{f}$ and $\mathrm{g}$ be maps from an intuitionistic Menger space (X, F, $\mathrm{L}, \mathrm{T}, \mathrm{S}$ ) into itself. The maps $\mathrm{f}$ and $\mathrm{g}$ are said to be compatible if for all $\mathrm{t}>0, \lim _{\mathrm{n} \rightarrow \infty}$ $\mathrm{F}_{\mathrm{fgx}_{\mathrm{n}}, \operatorname{gfx}_{\mathrm{n}}}(\mathrm{t})=1$ and $\mathrm{L}_{\mathrm{fgx}_{\mathrm{n}}, \operatorname{gfx}_{\mathrm{n}}}(\mathrm{t})=0$, whenever $\left\{\mathrm{x}_{n}\right\}$ is a sequence in $\mathrm{X}$ such that $\lim _{\mathrm{n} \rightarrow \infty} f \mathrm{x}_{\mathrm{n}}=\lim _{\mathrm{n} \rightarrow \infty} \mathrm{gx} \mathrm{x}_{\mathrm{n}}=\mathrm{z}$ for some $\mathrm{z} \in \mathrm{X}$.

Following Pant [29] we define R-weak commutivity for a pair of mappings in the intuitionistic Menger spaces

Definition 2.13. Let $(X, F, L, T, S)$ be an intuitionistic Menger space. Let $f$ and $\mathrm{g}$ be mappings on $\mathrm{X}$. The mappings $\mathrm{f}$ and $\mathrm{g}$ are said to be the point wise $\mathrm{R}$-weakly commuting on $\mathrm{X}$ if given $\mathrm{x}$ in $\mathrm{X}$ there exists positive real number $\mathrm{R}$ such that

$$
\begin{aligned}
& \mathrm{F}_{\text {fgx, gfx }}(\mathrm{t}) \geq \mathrm{F}_{\mathrm{fx}, \mathrm{gx}}\left(\frac{\mathrm{t}}{\mathrm{R}}\right) \text { and } \\
& \mathrm{L}_{\mathrm{fgx}, g \mathrm{fx}}(\mathrm{t}) \leq \mathrm{L}_{\mathrm{fx}, \mathrm{gx}}\left(\frac{\mathrm{t}}{\mathrm{R}}\right), \mathrm{t}>0 .
\end{aligned}
$$

Also two self maps $\mathrm{f}$ and $\mathrm{g}$ on a intuitionistic Menger space (X, F, L, T, S) are said to be R-weakly commuting if there exists some positive real number $\mathrm{R}$ such that

$$
\mathrm{F}_{\text {fgx, gfx }}(\mathrm{t}) \geq \mathrm{F}_{\mathrm{fx}, \mathrm{gx}}\left(\frac{\mathrm{t}}{\mathrm{R}}\right) \text { and }
$$




$$
\mathrm{L}_{\mathrm{fgx}, \mathrm{gfx}}(\mathrm{t}) \leq \mathrm{L}_{\mathrm{fx}, \mathrm{gx}}\left(\frac{\mathrm{t}}{\mathrm{R}}\right), \forall \mathrm{t}>0 \text { and each } \mathrm{x} \in \mathrm{X} .
$$

It should be noted that point wise R-weak commutativity is necessary, hence minimal condition for the existence of common fixed points of contractive type maps.

Definition 2.14 ([22]). Two self maps $\mathrm{f}$ and $\mathrm{g}$ on a intuitionistic Menger space $(\mathrm{X}, \mathrm{F}, \mathrm{L}, \mathrm{T}, \mathrm{S})$ are weakly commuting if they commute at their coincidence points.

Jesic and Babacev [21] proved the following theorem in intuitionistic fuzzy metric space.

Theorem A. Let $\left(\mathrm{X}, \mathrm{M}, \mathrm{N},{ }^{*}, \diamond\right)$ be complete intuitionistic fuzzy metric space. Let $f$ and $\mathrm{g}$ be $\mathrm{R}$-weakly commuting self mappings on $\mathrm{X}, \mathrm{g}$ is a continuous function, $\mathrm{g}(\mathrm{x})$ is IF-strongly bounded set and $\mathrm{g}(\mathrm{x}) \subseteq \mathrm{f}(\mathrm{x})$, satisfying the conditions:

$$
\begin{aligned}
& \mathrm{M}(\mathrm{g}(\mathrm{x}), \mathrm{g}(\mathrm{u}), \phi(\mathrm{t})) \geq \mathrm{M}(\mathrm{f}(\mathrm{x}), \mathrm{f}(\mathrm{u}), \mathrm{t}) \text { and } \\
& \mathrm{N}(\mathrm{g}(\mathrm{x}), \mathrm{g}(\mathrm{u}), \phi(\mathrm{t})) \leq \mathrm{N}(\mathrm{f}(\mathrm{x}), \mathrm{f}(\mathrm{u}), \mathrm{t}),
\end{aligned}
$$

for some continuous, nondecreasing function $\phi:(0, \infty) \rightarrow(0, \infty)$, which satisfies $\phi(\mathrm{t})<\mathrm{t}$ for all $\mathrm{t}>0$. Then $f$ and $g$ have a unique common fixed point.

Deshpande [7] improved Theorem A by omitting the continuity of mapping $\mathrm{g}$ and replacing R-weak commutativity at every point of X by (DS)-weak commutativity only at the coincidence points of $f$ and $g$ and proved the following:

Theorem B ([7]). Let $\left(\mathrm{X}, \mathrm{M}, \mathrm{N},{ }^{*}, \diamond\right)$ be a complete intuitionistic fuzzy metric space. Let $\mathrm{f}$ and $\mathrm{g}$ be self-mappings on $\mathrm{X}$. Let $\mathrm{g}(\mathrm{x})$ is IF-strongly bounded set and $\mathrm{g}(\mathrm{x}) \subseteq$ $\mathrm{f}(\mathrm{x})$, satisfying the conditions:

$$
\begin{aligned}
& \mathrm{M}(\mathrm{g}(\mathrm{x}), \mathrm{g}(\mathrm{y}), \phi(\mathrm{t})) \geq \mathrm{M}(\mathrm{f}(\mathrm{x}), \mathrm{f}(\mathrm{y}), \mathrm{t}) \text { and } \\
& \mathrm{N}(\mathrm{g}(\mathrm{x}), \mathrm{g}(\mathrm{y}), \phi(\mathrm{t})) \leq \mathrm{N}(\mathrm{f}(\mathrm{x}), \mathrm{f}(\mathrm{y}), \mathrm{t}),
\end{aligned}
$$

for some continuous, nondecreasing function $\phi:(0, \infty) \rightarrow(0, \infty)$, which satisfies $\phi(\mathrm{t})<\mathrm{t}$ for all $\mathrm{t}>0$. Then $f$ and $g$ have a coincidence point. Further if $f$ and $g$ are (DS)-weakly commuting at coincidence points then $f$ and $g$ have a unique common fixed point.

\section{Main Results}

Definition 3.1. Let $(X, F, L, T, S)$ be an intuitionistic Menger space and let $f$ and $g$ be self-mappings on $\mathrm{X}$. The mappings $\mathrm{f}$ and $\mathrm{g}$ are said to be $\left(\mathrm{DS}_{\mathrm{f}}\right)$-weakly commuting at $\mathrm{x} \in \mathrm{X}$ if there exists a positive real number $\mathrm{R}$ such that

$$
\begin{aligned}
& \mathrm{F}_{\mathrm{fgx}, \operatorname{ggx}}(\mathrm{t}) \geq \mathrm{F}_{\mathrm{fx}, \mathrm{gx}}\left(\frac{\mathrm{t}}{\mathrm{R}}\right) \text { and } \\
& \mathrm{L}_{\mathrm{fgx}, \operatorname{ggx}}(\mathrm{t}) \leq \mathrm{L}_{\mathrm{fx}, \operatorname{gx}}\left(\frac{\mathrm{t}}{\mathrm{R}}\right) .
\end{aligned}
$$


Here $\mathrm{f}$ and $\mathrm{g}$ are $\left(\mathrm{DS}_{\mathrm{f}}\right)$-weakly commuting on $\mathrm{X}$ if the above inequality holds for all $\mathrm{x} \in \mathrm{X}$.

Definition 3.2. Let $(X, F, L, T, S)$ be an intuitionistic Menger space and Let $f$ and $g$ be self-mappings on $\mathrm{X}$. The mappings $\mathrm{f}$ and $\mathrm{g}$ are said to be $\left(\mathrm{DS}_{\mathrm{g}}\right)$-weakly commuting at $\mathrm{x} \in \mathrm{X}$ if there exists a positive real number $\mathrm{R}$ such that

$$
\begin{aligned}
& \mathrm{F}_{\mathrm{gfx}, \mathrm{ffx}}(\mathrm{t}) \geq \mathrm{F}_{\mathrm{fx}, \mathrm{gx}}\left(\frac{\mathrm{t}}{\mathrm{R}}\right) \text { and } \\
& \mathrm{L}_{\mathrm{gfx}, \mathrm{ffx}}(\mathrm{t}) \leq \mathrm{L}_{\mathrm{fx}} \text { gx }\left(\frac{\mathrm{t}}{\mathrm{R}}\right) .
\end{aligned}
$$

Here $\mathrm{f}$ and $\mathrm{g}$ are $\left(\mathrm{DS}_{\mathrm{g}}\right)$-weakly commuting on $\mathrm{X}$ if the above inequality holds for all $\mathrm{x} \in \mathrm{X}$.

If the self-mappings $\mathrm{f}$ and $\mathrm{g}$ of $\mathrm{X}$ are both $\left(\mathrm{DS}_{\mathrm{f}}\right)$-weakly commuting as well as $\left(\mathrm{DS}_{\mathrm{g}}\right)$-weakly commuting then we say that $\mathrm{f}$ and $\mathrm{g}$ are (DS)-weakly commuting mappings.

Example 3.1. Let $X=[1,5]$ with the metric d defined by $d(x, y)=|x-y|$ for each $\mathrm{t} \in(0, \infty)$ define

$$
\begin{aligned}
& \mathrm{F}_{\mathrm{x}, \mathrm{y}}(\mathrm{t})=\mathrm{H}(\mathrm{t}-\mathrm{d}(\mathrm{x}, \mathrm{y})), \forall \mathrm{t}>0 \\
& \mathrm{~L}_{\mathrm{x}, \mathrm{y}}(\mathrm{t})=\mathrm{G}(\mathrm{t}-\mathrm{d}(\mathrm{x}, \mathrm{y})), \forall \mathrm{t}>0
\end{aligned}
$$

Clearly (X,F,L,T,S) be an intuitionistic Menger space where $\mathrm{T}$ is defined by $\mathrm{T}(\mathrm{a}, \mathrm{b})=\min \{\mathrm{a}, \mathrm{b}\}$ and $\mathrm{S}$ is defined by $\mathrm{S}(\mathrm{a}, \mathrm{b})=\max \{\mathrm{a}, \mathrm{b}\} \forall \mathrm{a}, \mathrm{b} \in[0,1]$ define $\mathrm{f}, \mathrm{g}$ : $\mathrm{X} \rightarrow \mathrm{X}$ by

$$
f(x)= \begin{cases}2 x & \text { if } x \in[0,1] \\ \frac{1}{3} & \text { if } x \in[1,5] .\end{cases}
$$

$\mathrm{g}(\mathrm{x})=\frac{1}{1+\mathrm{x}}$ for all $\mathrm{x} \in[0,5]$. Consider the sequence $\left\{\mathrm{x}_{\mathrm{n}}=2+\frac{1}{\mathrm{n}}: \mathrm{n} \geq 1\right\}$ in $\mathrm{X}$.

Then $\lim _{n \rightarrow \infty} f\left(x_{n}\right)=\frac{1}{3}=\lim _{n \rightarrow \infty} g\left(x_{n}\right)$. But

and $\quad \mathrm{L}_{\mathrm{fgx}_{\mathrm{n}}, \operatorname{gfx}_{\mathrm{n}}}(\mathrm{t})=\mathrm{G}\left(\mathrm{t}-\left|\frac{1}{3}-\frac{3}{4}\right|\right) \neq 0, \mathrm{t}>0$.

$$
\begin{aligned}
\lim _{\mathrm{n} \rightarrow \infty} \mathrm{F}_{\mathrm{fgx}_{\mathrm{n}}, \operatorname{gfx}_{\mathrm{n}}}(\mathrm{t})=\mathrm{H}\left(\mathrm{t}-\left|\frac{1}{3}-\frac{3}{4}\right|\right) \neq 1, \mathrm{t}>0 . \\
\mathrm{L}_{\mathrm{fgx}_{\mathrm{n}}, \text { gfx }_{\mathrm{n}}}(\mathrm{t})=\mathrm{G}\left(\mathrm{t}-\left|\frac{1}{3}-\frac{3}{4}\right|\right) \neq 0, \mathrm{t}>0 .
\end{aligned}
$$

Thus $\mathrm{f}$ and $\mathrm{g}$ are non compatible but we can observe that $\forall \mathrm{t} \in(0, \infty)$ and for $\mathrm{R} \geq$ $6 \mathrm{t}, \mathrm{f}$ and $\mathrm{g}$ are $\left(\mathrm{DS}_{\mathrm{f}}\right)$-weakly commuting at $\mathrm{x}=1$.

Further we observe that $2 \in[1,5]$ is coincidence point of $f$ and $g$ as $f(2)=g(2)=\frac{1}{3}$ but $\mathrm{fg}(2)=\frac{2}{3} \neq \mathrm{gf}(2)=\frac{3}{4}$. Thus $\mathrm{f}$ and $\mathrm{g}$ are not weakly compatible maps.

Also $f$ and $g$ are pointwise R-weakly commtative mappings but there does not exist a positive real number $\mathrm{R}$ such that

$$
\begin{aligned}
& \mathrm{F}_{\mathrm{fgx}, \mathrm{gfx}}(\mathrm{t}) \geq \mathrm{F}_{\mathrm{fx}, \mathrm{gx}}\left(\frac{\mathrm{t}}{\mathrm{R}}\right) \text { and } \\
& \mathrm{L}_{\mathrm{fgx}, \mathrm{gfx}}(\mathrm{t}) \leq \mathrm{L}_{\mathrm{fx}, \mathrm{gx}}\left(\frac{\mathrm{t}}{\mathrm{R}}\right) \text { for all } \mathrm{t}>0 \text { and each } \mathrm{x} \in \mathrm{X} .
\end{aligned}
$$


Example 3.2. Let $X=[1,10]$ with the metric $d$ defined by $d(x, y)=|x-y|$, for each $\mathrm{t} \in(0, \infty)$ define

$$
\begin{aligned}
& \mathrm{F}_{\mathrm{x}, \mathrm{y}}(\mathrm{t})=\mathrm{H}(\mathrm{t}-\mathrm{d}(\mathrm{x}, \mathrm{y})), \forall \mathrm{t}>0 \\
& \mathrm{~L}_{\mathrm{x}, \mathrm{y}}(\mathrm{t})=\mathrm{G}(\mathrm{t}-\mathrm{d}(\mathrm{x}, \mathrm{y})), \forall \mathrm{t}>0 .
\end{aligned}
$$

Clearly (X, F, L, T, S) be an intuitionistic Menger space where $\mathrm{T}$ is defined by $\mathrm{T}(\mathrm{a}, \mathrm{b})=\min \{\mathrm{a}, \mathrm{b}\}$ and $\mathrm{S}$ is defined by $\mathrm{S}(\mathrm{a}, \mathrm{b})=\max \{\mathrm{a}, \mathrm{b}\} \forall \mathrm{a}, \mathrm{b} \in[0,1]$ define $\mathrm{f}, \mathrm{g}:$ $\mathrm{X} \rightarrow \mathrm{X}$ by

$$
\begin{gathered}
\mathrm{f}(\mathrm{x})=\left\{\begin{aligned}
x & \text { if } 1 \leq \mathrm{x} \leq 5 \\
x-2 & \text { if } 5<\mathrm{x} \leq 10
\end{aligned}\right. \\
\mathrm{g}(\mathrm{x})=\left\{\begin{aligned}
3 & \text { if } 1 \leq \mathrm{x} \leq 5 \\
\frac{x+1}{2} & \text { if } 5<\mathrm{x} \leq 10 .
\end{aligned}\right.
\end{gathered}
$$

Consider the sequence $\left\{x_{n}=5+\frac{1}{n}: n \geq 1\right\}$ in $X$. Then $\lim _{n \rightarrow \infty} f\left(x_{n}\right)=3$ $=\lim _{\mathrm{n} \rightarrow \infty} \mathrm{g}\left(\mathrm{x}_{\mathrm{n}}\right)$. Also $\lim _{\mathrm{n} \rightarrow \infty} \mathrm{F}_{\mathrm{fgx}_{\mathrm{n}}, \mathrm{gfx}_{\mathrm{n}}}(\mathrm{t})=\mathrm{H}(\mathrm{t}-|3-3|)=\mathrm{H}(\mathrm{t})=1, \forall \mathrm{t}>0$ and $\mathrm{L}_{\mathrm{fgx}_{\mathrm{n}}, \operatorname{gfx}_{\mathrm{n}}}(\mathrm{t})=\mathrm{G}(\mathrm{t}-|3-3|)=\mathrm{G}(\mathrm{t})=0, \forall \mathrm{t}>0$.

Thus $\mathrm{f}$ and $\mathrm{g}$ are compatible. Therefore they are weakly compatible. Also for all positive real $\mathrm{R} \geq \frac{\mathrm{t}}{2}, \mathrm{f}$ and $\mathrm{g}$ are $\left(\mathrm{DS}_{\mathrm{f}}\right)$-weakly commuting at $\mathrm{x}=9$.

Also $f$ and $g$ are pointwise R-weakly commtative mappings but there does not exist a positive real number $\mathrm{R}$ such that

$$
\begin{aligned}
& \mathrm{F}_{\mathrm{fgx}, g f x}(\mathrm{t}) \geq \mathrm{F}_{\mathrm{fx}} \text { gx }\left(\frac{\mathrm{t}}{\mathrm{R}}\right) \text { and } \\
& \mathrm{L}_{\mathrm{fgx}, \mathrm{gfx}}(\mathrm{t}) \leq \mathrm{L}_{\mathrm{fx}} \text {,gx }\left(\frac{\mathrm{t}}{\mathrm{R}}\right) \text { for all } \mathrm{t}>0 \text { and each } \mathrm{x} \in \mathrm{X} .
\end{aligned}
$$

Theorem 3.1. Let $(\mathrm{X}, \mathrm{F}, \mathrm{L}, \mathrm{T}, \mathrm{S})$ be a complete intuitionistic Menger space. Let $\mathrm{f}$ and $\mathrm{g}$ be self-mappings on $\mathrm{X}$. Let $\mathrm{g}(\mathrm{x})$ is IM-strongly bounded set and $\mathrm{g}(\mathrm{x}) \subseteq \mathrm{f}(\mathrm{X})$ satisfying the condition

(1) $\quad \mathrm{F}_{\mathrm{gx}, \text { gy }} \phi(\mathrm{t}) \geq \mathrm{F}_{\mathrm{fx}}, \mathrm{fy}(\mathrm{t}), \mathrm{L}_{\mathrm{gx}}, \mathrm{gy} \phi(\mathrm{t}) \leq \mathrm{L}_{\mathrm{fx}}$, fy $(\mathrm{t})$ for all $\mathrm{x}, \mathrm{y} \in \mathrm{X}$, for some continuous nondecresing function $\phi:(0, \infty) \rightarrow(0, \infty)$ which satisfies $\phi(\mathrm{t})$ $<\mathrm{t}$ for all $\mathrm{t}>0$. Then $\mathrm{f}$ and $\mathrm{g}$ have a coincidence point. Further if $f$ and $g$ are (DS)-weakly commuting at coincidence points then $\mathrm{f}$ and $\mathrm{g}$ have a unique common fixed point.

Proof. Let $\mathrm{x}_{0} \in \mathrm{X}$ be an arbitrary point. Since $\mathrm{g}(\mathrm{X}) \subseteq \mathrm{f}(\mathrm{X})$, there exists a $\mathrm{x}_{1} \in$ $X$ such that $g\left(x_{0}\right)=f\left(x_{1}\right)$. By induction a sequence $\left\{x_{n}\right\}$ can be chosen such that $\mathrm{g}\left(\mathrm{x}_{\mathrm{n}}\right)=\mathrm{f}\left(\mathrm{x}_{\mathrm{n}+1}\right)$. Let us consider nested sequence of non-empty closed sets defined by $\mathrm{F}_{\mathrm{n}}=\left\{\overline{\operatorname{gx}_{\mathrm{n}}, \mathrm{gx}_{\mathrm{n}+1}, \ldots \ldots \ldots . .} \mathrm{n} \in \mathrm{N}\right.$. We shall prove that the family $\left\{\mathrm{F}_{\mathrm{n}}\right\}_{\mathrm{n} \in \mathrm{N}}$ has intuitionistic Menger diameter zero. 
In this sense, Let $r \in(0,1)$ and $t>0$ be arbitrary. From $F_{k} \in \overline{g(x)}$ it follows that $\mathrm{F}_{\mathrm{k}}$ is an IM-Strongly bounded set for arbitrary $\mathrm{k} \in \mathrm{N}$. It means that there exists $\mathrm{t}_{0}$ $>0$ such that

$$
\mathrm{F}_{\mathrm{x}, \mathrm{y}}\left(\mathrm{t}_{0}\right)>1-\mathrm{r} \text { and } \mathrm{L}_{\mathrm{x}, \mathrm{y}}\left(\mathrm{t}_{0}\right)<\mathrm{r} \text { for all } \mathrm{x}, \mathrm{y} \in \mathrm{F}_{\mathrm{K}} \text {. }
$$

From $\lim _{\mathrm{n} \rightarrow \infty} \phi^{\mathrm{n}}\left(\mathrm{t}_{0}\right)=0$, we conclude that there exists $\mathrm{m} \in \mathrm{N}$ such that $\phi^{\mathrm{m}}\left(\mathrm{t}_{0}\right)<$ t. Let $\mathrm{n}=\mathrm{m}+\mathrm{k}$ and $\mathrm{x}, \mathrm{y} \in \mathrm{F}_{\mathrm{n}}$ be arbitrary. There exists sequence $\left\{\operatorname{gx}_{\mathrm{n}_{(\mathrm{i})}}\right\},\left\{\operatorname{gx}_{\mathrm{n}_{(\mathrm{j})}}\right\}$ in $\mathrm{F}_{\mathrm{n}}(\mathrm{n}(\mathrm{i}), \mathrm{n}(\mathrm{j}) \geq \mathrm{n}$ for all $\mathrm{i}, \mathrm{j} \in \mathrm{N})$ such that $\lim _{\mathrm{n} \rightarrow \infty} \mathrm{gx}_{\mathrm{n}_{(\mathrm{i})}}=\mathrm{x}$ and $\lim _{\mathrm{n} \rightarrow \infty} \mathrm{gx}_{\mathrm{n}_{(\mathrm{j})}}=\mathrm{y}$.

From (1) we have

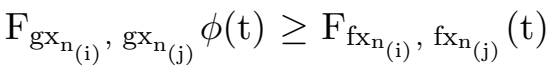

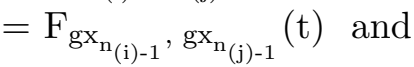

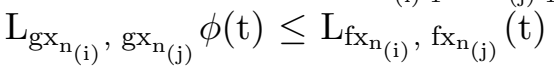

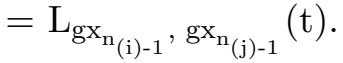

Thus by induction we get

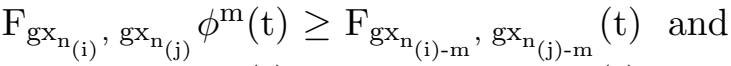

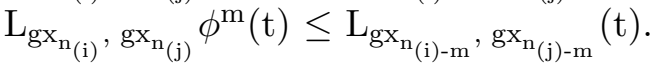

Since $\phi^{\mathrm{m}}\left(\mathrm{t}_{0}\right)<\mathrm{t}$ and because the distance distribution function and the nondistance distribution function are nondecreasing and nonincreasing respectively, from the last inequalities it follows that

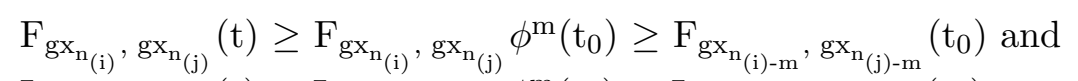

As $\left\{\operatorname{gx}_{\mathrm{n}_{(\mathrm{i})-\mathrm{m}}}\right\}$ and $\left\{\operatorname{gx}_{\mathrm{n}_{(\mathrm{j})-\mathrm{m}}}\right\}$ are sequences in $\mathrm{F}_{\mathrm{k}}$ from (1) it follows that

$$
\begin{aligned}
& \mathrm{F}_{\mathrm{gx}_{\mathrm{n}_{(\mathrm{i})-m}}, \mathrm{gx}_{\mathrm{n}_{(\mathrm{j})-\mathrm{m}}}}\left(\mathrm{t}_{0}\right)>1-\mathrm{r} \\
& \mathrm{L}_{\mathrm{gx}_{\mathrm{n}_{(\mathrm{i})-m}}, \mathrm{gx}_{\mathrm{n}_{(\mathrm{j})-\mathrm{m}}}}\left(\mathrm{t}_{0}\right)<\mathrm{r}
\end{aligned}
$$

for all $i, j \in N$. Finally from (i) to (iii) we conclude that

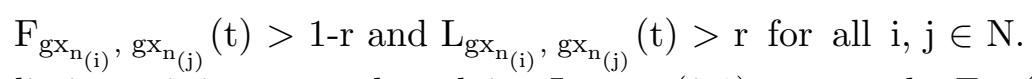

Taking the limits as $\mathrm{i}, \mathrm{j} \rightarrow \infty$ and applying Lemma(2.1), we get the $\mathrm{F}_{\mathrm{x}, \mathrm{y}}(\mathrm{t})>1-\mathrm{r}$ and $\mathrm{L}_{\mathrm{x}, \mathrm{y}}(\mathrm{t})<\mathrm{r}$ for all $\mathrm{x}, \mathrm{y} \in \mathrm{F}_{\mathrm{n}}$ that is family has intuitionistic Menger diameter zero.

Applying Theorem (2.3) we conclude that this family has non-empty intersection, which consists of exactly one point $z$. Since the family $\left\{F_{n}\right\}_{n \in N}$ has intuitionistic Menger diameter zero and $\mathrm{z} \in \mathrm{F}_{\mathrm{n}}$ for all $\mathrm{n} \in \mathrm{N}$ then for each $\mathrm{r} \in(0,1)$ and each $\mathrm{t}>$ 0 there exists $n_{0} \in N$ such that for all $n \geq n_{0}$ hold.

$$
\mathrm{F}_{\mathrm{gx}_{\mathrm{n}}, \mathrm{z}}(\mathrm{t})>1-\mathrm{r} \text { and } \mathrm{L}_{\mathrm{gx}_{\mathrm{n}}, \mathrm{z}}(\mathrm{t})<\mathrm{r} \text {. }
$$

From the last it follows that for each $r \in(0,1)$ hold 
Taking that $\mathrm{r} \rightarrow 0$ we get

$$
\lim _{n \rightarrow \infty} F_{g x_{n}, z}(t)>1-r \text { and } \lim _{n \rightarrow \infty} L_{g x_{n}, z}(t)<r .
$$

$$
\lim _{\mathrm{n} \rightarrow \infty} \mathrm{F}_{\mathrm{gx}_{\mathrm{n}}, \mathrm{z}}(\mathrm{t})=1 \text { and } \lim _{\mathrm{n} \rightarrow \infty} \mathrm{L}_{\mathrm{gx}_{\mathrm{n}}, \mathrm{z}}(\mathrm{t})=0 .
$$

That is $\lim _{n \rightarrow \infty} g x_{n}=z$ From the definition of sequence $\left\{f_{n}\right\}$ it follows that

$$
\lim _{n \rightarrow \infty} f x_{n}=z
$$

Since $\mathrm{g}(\mathrm{x}) \subseteq \mathrm{f}(\mathrm{x})$, there exists a point $\mathrm{u} \in \mathrm{X}$ such that $\mathrm{z}=\mathrm{f}(\mathrm{u})$. Then using (1), we have

Letting $\mathrm{n} \rightarrow \infty$ we get

$$
\begin{aligned}
& \mathrm{F}_{\mathrm{g}(\mathrm{u}), \mathrm{g}\left(\mathrm{x}_{\mathrm{n}}\right)} \phi(\mathrm{t}) \geq \mathrm{F}_{\mathrm{f}(\mathrm{u}), \mathrm{f}\left(\mathrm{x}_{\mathrm{n}}\right)}(\mathrm{t}) \quad \text { and } \\
& \mathrm{L}_{\mathrm{g}(\mathrm{u}), \mathrm{g}\left(\mathrm{x}_{\mathrm{n}}\right)} \phi(\mathrm{t}) \leq \mathrm{L}_{\mathrm{f}(\mathrm{u}), \mathrm{f}\left(\mathrm{x}_{\mathrm{n}}\right)}(\mathrm{t}) .
\end{aligned}
$$

$$
\begin{aligned}
& \mathrm{F}_{\mathrm{g}(\mathrm{u}), \mathrm{z}} \phi(\mathrm{t}) \geq \mathrm{F}_{\mathrm{z}, \mathrm{z}}(\mathrm{t})=1 \quad \text { and } \\
& \mathrm{L}_{\mathrm{g}(\mathrm{u}), \mathrm{z}} \phi(\mathrm{t}) \leq \mathrm{L}_{\mathrm{z}, \mathrm{z}}(\mathrm{t})=0 .
\end{aligned}
$$

Since $\mathrm{F}_{\mathrm{g}(\mathrm{u}), \mathrm{z}}(\mathrm{t}) \geq \mathrm{F}_{\mathrm{g}(\mathrm{u}), \mathrm{z}} \phi(\mathrm{t})$ and

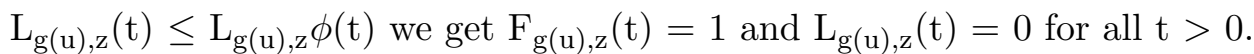

Thus $\mathrm{g}(\mathrm{u})=\mathrm{z}$, therefore $\mathrm{f}(\mathrm{u})=\mathrm{g}(\mathrm{u})=\mathrm{z}$ that is $\mathrm{u}$ is coincidence point of $\mathrm{f}$ and $\mathrm{g}$.

Since $f$ and $g$ are (DS)-weakly commuting at coincidence point so $f$ and $g$ are $\left(\mathrm{DS}_{\mathrm{f}}\right)$-weakly commuting at coincidence points. Threfore there exists a positive real number $\mathrm{R}$ such that

$$
\mathrm{F}_{\text {fgu,ggu }}(\mathrm{t}) \geq \mathrm{F}_{\mathrm{fu}, \mathrm{gu}}\left(\frac{\mathrm{t}}{\mathrm{R}}\right) \text { and } \mathrm{L}_{\mathrm{fgu}, \mathrm{ggu}}(\mathrm{t}) \leq \mathrm{L}_{\mathrm{fu}, \mathrm{gu}}\left(\frac{\mathrm{t}}{\mathrm{R}}\right) .
$$

Thus $\mathrm{F}_{\text {fgu,ggu }}(\mathrm{t})=$ 1and $\mathrm{L}_{\mathrm{fgu}, \mathrm{ggu}}(\mathrm{t})$ and $(\mathrm{t})=0$. So fgu=ggu that is $\mathrm{fz}=$ gz. Again using (1), we have

$$
\mathrm{F}_{\mathrm{g}\left(\mathrm{x}_{\mathrm{n}}\right), \mathrm{g}(\mathrm{z})} \phi(\mathrm{t}) \geq \mathrm{F}_{\mathrm{f}\left(\mathrm{x}_{\mathrm{n}}\right), \mathrm{f}(\mathrm{z})}(\mathrm{t}) \text { and } \mathrm{L}_{\mathrm{g}\left(\mathrm{x}_{\mathrm{n}}\right), \mathrm{g}(\mathrm{z})} \phi(\mathrm{t}) \leq \mathrm{L}_{\mathrm{f}\left(\mathrm{x}_{\mathrm{n}}\right), \mathrm{f}(\mathrm{z})}(\mathrm{t}) .
$$

Letting $\mathrm{n} \rightarrow \infty$ we have

$\mathrm{F}_{\mathrm{z}, \mathrm{g}(\mathrm{z})} \phi(\mathrm{t}) \geq \mathrm{F}_{\mathrm{z}, \mathrm{g}(\mathrm{z})}(\mathrm{t})$ and $\mathrm{L}_{\mathrm{z}, \mathrm{g}(\mathrm{z})} \phi(\mathrm{t}) \leq \mathrm{L}_{\mathrm{z}, \mathrm{g}(\mathrm{z})}(\mathrm{t})$ for all $\mathrm{t}>0$. Applying Lemma (2.3), we get $\mathrm{g}(\mathrm{z})=\mathrm{z}$ thus $\mathrm{f}(\mathrm{z})=\mathrm{g}(\mathrm{z})=\mathrm{z}$.

Let us prove that $\mathrm{z}$ is a unique common fixed point of $\mathrm{f}$ and $\mathrm{g}$. For this purpose let us suppose that there exists another common fixed point $\mathrm{w}$ of $\mathrm{f}$ and $\mathrm{g}$ then by (1) we have

$\mathrm{F}_{\mathrm{g}(\mathrm{z}), \mathrm{g}(\mathrm{w})} \phi(\mathrm{t}) \geq \mathrm{F}_{\mathrm{f}(\mathrm{z}), \mathrm{f}(\mathrm{w})}(\mathrm{t})$ and $\mathrm{L}_{\mathrm{g}(\mathrm{z}), \mathrm{g}(\mathrm{w})} \phi(\mathrm{t}) \leq \mathrm{L}_{\mathrm{f}(\mathrm{z}), \mathrm{f}(\mathrm{w})}(\mathrm{t})$ for all $\mathrm{t}>0$.

Thus we have

$$
\mathrm{F}_{\mathrm{z}, \mathrm{u}} \phi(\mathrm{t}) \geq \mathrm{F}_{\mathrm{z}, \mathrm{u}}(\mathrm{t}) \text { and } \mathrm{L}_{\mathrm{z}, \mathrm{u}} \phi(\mathrm{t}) \leq \mathrm{L}_{\mathrm{z}, \mathrm{u}}(\mathrm{t}) \text { for all } \mathrm{t}>0 .
$$

Applying Lemma(2.3) it follows that $\mathrm{z}=\mathrm{w}$.

Example 3.3. Let $X=[0,10)$ with the metric d defined by $d(x, y)=|x-y|$ and for each $t \in(0,1)$ define 


$$
\begin{aligned}
& \mathrm{F}_{\mathrm{x}, \mathrm{y}}(\mathrm{t})=\mathrm{H}(\mathrm{t}-\mathrm{d}(\mathrm{x}, \mathrm{y})) \forall \mathrm{t}>0 \quad \text { and } \\
& \mathrm{L}_{\mathrm{x}, \mathrm{y}}(\mathrm{t})=\mathrm{G}(\mathrm{t}-\mathrm{d}(\mathrm{x}, \mathrm{y})) \forall \mathrm{t}>0 .
\end{aligned}
$$

Clearly (X,F,L,T,S) be a complete intuitionistic Menger space where $\mathrm{T}$ is defined by $\mathrm{T}(\mathrm{a}, \mathrm{b})=\min \{\mathrm{a}, \mathrm{b}\}$ and $\mathrm{S}$ is defined by $\mathrm{S}(\mathrm{a}, \mathrm{b})=\max \{\mathrm{a}, \mathrm{b}\}$. define $\mathrm{f}, \mathrm{g}: \mathrm{X} \rightarrow \mathrm{X}$

$$
\mathrm{f}(\mathrm{x})= \begin{cases}1 & \text { if } \mathrm{x}=1 \\ x & \text { if } \mathrm{x} \neq 1\end{cases}
$$

and

$$
g(x)=\left\{\begin{aligned}
1 & \text { if } x=1 \\
\frac{1}{2 x+1} & \text { if } x \neq 1
\end{aligned}\right.
$$

$\phi(\mathrm{t})=\frac{\mathrm{t}}{2}, \mathrm{t}>0$. Then $\mathrm{g}(\mathrm{x}) \subseteq \mathrm{f}(\mathrm{x})$.

We can see that there exists no increasing or decreasing sequence $\left\{\mathrm{x}_{\mathrm{n}}\right\}$ in $\mathrm{X}$ for which $\lim _{n \rightarrow \infty} f\left(x_{n}\right)=\lim _{n \rightarrow \infty} g\left(x_{n}\right)$.

Thus the mappings $\mathrm{f}$ and $\mathrm{g}$ are not compatible. But we can observe that the mappings are (DS)-weakly commuting at coincidence point $\mathrm{x}=1$ for all positve real values of R. Further we can observe that condition (1) is satisfied for $\phi(t)=\frac{t}{2}$. Thus all the conditions of theorem 3.1 are satisfied. So $f$ and $g$ have a unique common fixed point. It is easy to see that this point is $\mathrm{x}=1$.It should be noted that both the mappings involued in this example are discontinuous even at the common fixed point $\mathrm{x}=1$.

Remark 2.7. (i) We improve Theorem A in sense that we prove our Theorem 3.1 without assuming continuty of any mapping.

(ii) Theorem 3.1 is intuitionistice Menger version of Theorem B.

(iii) In Theorem 3.1, (DS)-weak commutativity for mappings $f$ and $g$ at coincidence points can be replaced by the condition R-weak commutativity for mappings $\mathrm{f}$ and $\mathrm{g}$ at coincidence points.

(iv) We improve Theorem B in the settings of intuitionistice Menger spaces.

\section{REFERENCES}

1. Amini M. \& Saadati R.: Some properties of continuous t-norms and s-norms. Int. J Pure Appl Math. 16 (2004), 157-164.

2. Boyd D.W. \& Wong J.S.W.: On nonlinear contractions. Proc. Amer. Math. Soc. 20 (1969), 458-464. 
3. Bylka C.: Fixed point theorems of Matkowski on probabilistic metric spaces. Demonstratio Math. 29 (1996), 158-164.

4. Cho Y.J., Murthy P.P. \& Stojakovic M.: Compatible mappings of type (A) and common fixed points in Menger spaces. Com. Korean Math. J. 7 (1992), 325-339.

5. Civic L.B.: Milovanovic, Arandjelovic M.M.: Common fixed point theorem for R-weak commuting mappings in Menger spaces. J. Indian Acad. Math. 22 (2000), 199-210.

6. Dedeic R. \& Sarapa N.: A common fixed point theorem for three mappings on Menger spaces. Math. Japanica 34 (1989), no. 6, 919-923.

7. Deshpande B.: Fixed point and (DS)-weak commutativity condition in intuitionistic fuzzy metric space. Chaos, Solitons \& Fractals 42 (2009), 2722-2728.

8. EI Naschie M.S.: On the uncertainly of cantorian geometry and the two-slit experiment. Chaos, Solitons and Fractals 9 (1998), no. 3, 517-529.

9. __ On the verification of heterotic strings theory and $\mathrm{e}^{(\infty)}$ theory. Chaos, Solitons and Fractals 11 (2000), 2397-2408.

10. _ : A review of applications and results of E-infinity theory. Int J. Nonlinear Sci Numer Simulet 8 (2007), no. 1, 11-20.

11. George A. \& Veeramani P.: On some result in fuzzy metric space. Fuzzy Sets and Systems 64 (1994), 395-399.

12. __ On some result of analysis for fuzzy metric spaces. Fuzzy Sets and Systems $\mathbf{9 0}$ (1997), 365-368.

13. Gregori V. \& Romaguera S.: Characterzing completable fuzzy metric spaces. Fuzzy Sets and Systems 144 (2004), 411-420.

14. __ On completion of fuzzy metric spaces. Fuzzy Sets and Systems 130 (2002), 399-404.

15. ___ Some properties of fuzzy metric spaces. Fuzzy Sets and Systems 115 (2000), 485-489.

16. Hadzic O.: A fixed point theorem in Menger spaces. Publ. Inst. Math. Beograd 20 (1979), 107-112.

17. _ Some theorems on the fixed points in probabilistic metric and random normed spaces. Boll. Un. Mat. Ital. 13 (1981), no. 5, 1-11.

18. ___ Fixed point theory in probabilistic metric spaces. Novi Sad : Serbian Academy of Science and Arts, 1995.

19. _ Fixed point theory in topological vector space. Novi Sad : University of Novi Sad, Institute of Mathematics, 1984.

20. Hu C.: C-structure of FTS. V:Fuzzy metric spaces. J. Fuzzy Math. 3 (1995), 711-721.

21. Jesic S.N. \& Babacev N.A.: Common fixed point theorems in intuitionistic fuzzy metric space and L-fuzzy metric spaces with nonlinear contractive condition. Chaos Solitons and Fractals 37 (2008), 675-687. 
22. Jungck G. \& Rhoades B.E.: Fixed point for set valued functions without continuity. Indian J. Pure Appl. Math. 29 (1998), no. 3, 227-238.

23. Kubiaczyk I. \& Deshpande B.: Comments on a fixed point theorem in Menger space through weak compatibility. Italian J. Pure and Appl. Math. 23 (2008), 137-146.

24. Kutukcu S., Tuna A. \& Yakut A.T.: Generalized contraction mapping principle in intuitionistic Menger spaces and application to differential equations. Applied Mathematics and Mechanics (English Edition) 28 (2007), no. 6, 799-809.

25. Lowen R.: Fuzzy set theory. Dordrecht : Kluwer Academic Publishers, 1996.

26. Menger K.: Statistical Metric. Proc Nat Acad Sci USA 28 (1942), 535-537.

27. Mishra S.N.: Common fixed points of compatible mappings in PM-spaces. Math. Japanica 36 (1991), no. 2, 283-289.

28. O'Regan D. \& Sadaati R.: Nonlinear contraction theorems in probabilistic spaces. Appl. Math. Comput. 195 (2008), 86-93.

29. Pant R.P.: Common fixed point of non commuting mappings. J. Math. Anal. Appl. 188 (1994), 436-40.

30. Park J.H.: Intuitionistic fuzzy metric spaces. Chaos, Solitons \& Fractals 22 (2004), 1039-1046.

31. Pathak H.K. Cho Y.J. \& Kang S.M.: Remarks on R-weakly commuting mappings and common fixed point theorems. Bull. Korean Math. Soc. 34 (1997), 247-257.

32. Pathak H.K., Kang S.M. \& Baek J.H.: Weak compatible mappings of type (A) and common fixed point in Menger spaces. Commun. Korean Math. Soc. 10 (1995), no. 1, 67-83.

33. Radu V.: On some contraction principle in Menger spaces. An Univ. Timisoara, Stiinte Math. 22 (1984), 83-88.

34. __ On some contraction type mappings in Menger spaces. An Univ. Timisoara, Stiinte Math. 23 (1985), 61-65.

35. Rashwan R.A. \& Hedar A.: On common fixed point theorems of compatible mappings in Menger spaces. Demonstratio Math. 31 (1998), no. 3, 537-546.

36. Schweizer B. \& Sklar A.: Probabilistic metric spaces. Elservier/North-Holland, New York, 1983.

37. Sehgal V.M. \& Bharucha-Reid A.T.: Fixed points of contraction mappings on probabilistic metric spaces. Math. System Theory 6 (1972), 97-102.

38. Serstnev A.N.: On the motion of a random normed space. Dokl, Akad, Nauk, SSSR 149 (1963), 280-283(English translation in Soviet Math, Dokl.) 4 (1963), 388-390.

39. Sharma S. \& Bagvan A.: Common fixed point theorem for six mappings in Menger space. Fasciculi Mathematici 37 (2007), 67-77.

40. Sharma S. \& Deshpande B.: Common fixed point theorems for weakly compatible mappings without continuity in Menger spaces. Pure Appl. Math. 10 (2003), no. 2, 133-144. 
41. : Common fixed point theorems for non-compatible mappings and Meir-Keeler type contractive condition in fuzzy metric space. International Review of Fuzzy Mathematics 1 (2006), no. 2, 147-159.

42. __ : A fixed point theorem in intuitionistic fuzzy metric spaces by using new commutativity condition. Submitted for publication.

43. _ C Compatible mappings of type (I) and (II) on intuitionistic fuzzy metric spaces in consideration of common fixed point. Commun. Korean Math. Soc. 24 (2009), no. 2, 197-214.

44. Sharma S., Deshpande B. \& Tiwari R.: Common fixed point theorems for finite numbers of mappings without continuity and compatibility in Menger spaces. J. Korean Soc. Math. Educ. Ser. B: Pure Appl. Math. 15 (2008), no. 2, 135-151.

45. Sherwood H.: Complete probabilistic metric spaces. Z. Wahrsch. Verw. Gebiete 20 (1971), 117-128.

46. Stojakovic M.: Common fixed point theorem in probabilistic metric spaces and its applications. Glasnik Mat. 23 (1988), 203-211.

47. __ C Common fixed point theorems in complete metric and probabilistic metric spaces. Bull Austral. Math. Soc. 36 (1987), 73-88.

48. : Fixed point theorem in probabilistic metric spaces. Kobe J. Math. 2 (1985), $1-9$.

49. Vasuki R.: Common fixed point for R-weakly commuting maps in fuzzy metric space. Indian J. Pure Appl. Math. 30 (1999), no. 4, 419-423.

${ }^{a}$ Department of Mathematics, Madhav Science College, Ujuain (M. P.), India

Email address: sksharma2005@yahoo.com

b Department of Mathematics, Govt. Arts \& Science P. G. College, Ratlam-457001 (M. P.), INDIA

Email address: bhavnadeshpande@yahoo.com

${ }^{\mathrm{c}}$ Department of Mathematics, Govt. Girls College, Ratlam-457001 (M. P.), India

Email address: s.chouhan31@gmail.com 